\title{
РАЗРАБОТКА ЛИПОСОМАЛЬНЫХ ФОРМ ЛЕКАРСТВЕННЫХ ПРЕПАРАТОВ: МЕТОДЫ ОЦЕНКИ И ПОКАЗАТЕЛИ КАЧЕСТВА
}

\author{
Е. В. Мельникова, Д. В. Горячев, А. А. Чапленко ${ }^{凶}$, М. А. Водякова, А. Р. Сайфутдинова, В. А. Меркулов \\ Федеральное государственное бюджетное учреждение «Научный центр экспертизы средств медицинского применения» \\ Министерства здравоохранения Российской Федерации, Москва
}

\begin{abstract}
Одним из трендов фармации на сегодняшний день является применение наноструктурных компонентов для производства лекарств, в частности для направленной доставки лекарственных средств в заданную область организма, органа или клетки. К нанопрепаратам авторы относят средства, содержащие дендримеры, нанокристаллы, мицеллы, липосомы, а также полимерные наночастицы. В настоящее время липосомы - одни из наиболее исследованных наночастиц, которые рассматривают как современные и эффективные средства доставки различных препаратов. Однако увеличение сложности структуры препарата неизбежно приводит к увеличению числа критических точек производства, а также к расширению списка показателей качества. Наряду с классическими показателями качества авторы считают необходимым оценивать также физико-химические свойства липосомной фракции: форму, размер и заряд частиц; эффективность конъюгации маркеров; равномерность распределения действующего вещества. Мы полагаем, что для контроля ключевых параметров липосом целесообразно использовать динамическое и лазерное светорассеяние в сочетании с электрофорезом, дифференциальную сканирующую калориметрию, криорасщепляющую электронную микроскопию, ядерный магнитный резонанс, лазерную дифракцию и гель-фильтрацию.
\end{abstract}

Ключевые слова: липосомы, нанопрепараты, контроль качества, нормативные документы

$\checkmark$ Для корреспонденции: Александр Андреевич Чапленко

ул. Щукинская, д. 6, корп. 1, г. Москва, 127051; chaplenko@Expmed.ru

Статья получена: 29.06.2018 Статья принята к печати: 02.09.2018

DOI: $10.24075 /$ vrgmu.2018.092

\section{DEVELOPMENT OF LIPOSOMAL DRUG FORMULATIONS: QUALITY ATTRIBUTES AND METHODS FOR QUALITY CONTROL}

\author{
Melnikova EV, Goryachev DV, Chaplenko AA $\bowtie$, Vodyakova MA, Sayfutdinova AR, Merkulov VA
}

Scientific Centre for Expert Evaluation of Medicinal Products

of the Ministry of Health of the Russian Federation, Moscow

The use of nanostructured components in drug manufacturing and, more specifically, targeted drug delivery has recently become a major trend in the pharmaceutical industry. Nanodrugs encompass a wide range of pharmaceutical agents containing dendrimers, nanocrystals, micelles, liposomes, and polymer nanoparticles. Liposomes are the most well-studied nanoparticles and effective drug carriers. However, the more complex their structure is, the more process controls are needed and the more quality attributes have to be monitored, including the chemical properties of the liposomal fraction such as the shape, size and charge of the nanoparticle, conjugation efficacy, and distribution of the active ingredient. We believe that quality control of key liposome characteristics should rely on dynamic and laser light scattering coupled with electrophoresis, differential scanning calorimetry, cryo-electron microscopy, nuclear magnetic resonance, laser diffraction analysis, and gel filtration chromatography.

Keywords: liposomes, nanodrugs, quality control, guidance documents

$\triangle$ Correspondence should be addressed: Alexander A. Chaplenko

Schukinskaya 6, bl. 1, Moscow, 127051; chaplenko@Expmed.ru

Received: 29.06.2018 Accepted: 02.09.2018

DOI: $10.24075 /$ brsmu.2018.092

Регулирование всех фармакокинетических параметров лекарственного средства (всасывания, распределения, выведения и биотрансформации), обеспечение селективного действия на целевые органы и мишени наряду с безопасностью и минимизацией нежелательных реакций и побочных эфффектов являются главными задачами фармацевтической отрасли. Одним из трендов на сегодняшний день является применение наноструктурных компонентов, в частности, для направленной доставки лекарственных средств (ЛС) в заданную область организма, органа или клетки. В законодательстве Российской Федерации отсутствуют понятия «нанопрепаратов» или «нанолекарств», фрактически к ним относят лекарственные препараты (ЛП), представляющие собой или содержащие в своем составе наночастицы. Преимущественно данное определение используют в отношении форм ЛС на основе липосом и мицелл, в этих случаях наноструктуры выполняют функции транспорта активного вещества внутри организма, пролонгации всасывания, повышения стабильности и т. д., или для ЛС, обладающих наноструктурой в связи с физико-химическими особенностями действующих веществ (например, препараты железа для лечения анемии могут содержать атомы железа (III), стабилизированного углеводным комплексом, что определяет их наноколлоидную структуру). В настоящее время мы разрабатываем руководство по оценке качества и исследованию 
лекарственных средств на основе липосом, мицелл и содержащих наночастицы.

Особенности состава нанопрепаратов обусловливают индивидуальные подходы к оценке их качества. Например, отдельные специфические показатели липосомных препаратов (размер наночастиц, морфология поверхности, поверхностный заряд) определяют их качество, поскольку могут оказывать большое влияние на следующие фармакокинетические и фармакодинамические свойства in vivo:

- скорость высвобождения действующего вещества из липосом, что может влиять на фармакокинетику (ФК) и фармакодинамику (ФД) и, таким образом, на профиль безопасности и эффеективности ЛП;

- биологическую доступность активного вещества, заключенного в липосому, его биотрансформацию и выведение.

ФК инкапсулированного вещества зависит от ФК носителя, которая обусловлена физико-химическими свойствами материала наночастицы, также следует учитывать взаимодействия между компонентами наночастицы, действующим веществом и биологической средой организма.

K нанопрепаратам авторы относят препараты, содержащие дендримеры, нанокристаллы, мицеллы, липосомы, а также полимерные наночастицы. В настоящее время липосомы - одни из наиболее изученных наночастиц, которые можно рассматривать как эфрфективные средства доставки различных ЛП. За последние годы мировая фрармацевтическая промышленность выпустила более 20 липосомных препаратов, которые применяют преимущественно в онкологии (Dauno Xome (Gilead, NeXstar), Doxil (Alza, Sequus), Caelyx (Schering-Plough), Myocet (Elan, TLC)) или в лечении грибковых инфекций (AmBisome, ABELSET (Gilead, NeXstar)) [1]. Учитывая особенности транспорта, транслокацию через гистогематические барьеры, клеточные мембраны и метаболические трансформации, липосомные фармакологические препараты обладают уникальными свойствами, связанными, прежде всего, с особенностями их ФК.

В статье обобщены и проанализированы данные по применению различных типов липосом для доставки ЛП, а также определены особенности оценки качества липосомных нанопрепаратов.

\section{Разновидности липосом и их применение в фармации}

Липосомы - везикулярные структуры, содержимое которых ограничено липидной мембраной, образуемой амфифильными молекулами. В последнее время липосомы превратились из простой модели, имитирующей клеточные мембраны, в объект активных научных исследований и практического применения [2]. Главная цель использования липосом в качестве носителей ЛП заключается в селективном накоплении действующих веществ в патологических очагах (опухолях, воспаленных тканях), что связано с такой способностью липосом, как пассивное нацеливание: размер пор между капиллярами в очагах воспаления или в опухолях (210-1000 нм) значительно превышает размер пор в нормальных тканях и органах (около 40 нм). Таким образом, липосомы размером менее 200 нм не могут выйти из кровотока нигде, кроме как в зонах воспаления (исключение составляет мозг, в котором, как правило, опухоль имеет меньшие поры, равные 7-100 нм [3, 4]), а у активного вещества, заключенного в липосомы, меньше возможности достичь органов, где оно может оказать токсическое действие. Так, например, липосомный доксорубицин проявляет в 2-3 раза меньшую токсичность по сравнению с раствором препарата [5].

В случае направленного липосомного транспорта применение антител к эндотелиальным белкам-мишеням, селективным для сосудов различных органов, позволяет многократно повысить адресность наноконтейнерной доставки биологически активных веществ и ДНК [6-9].

K настоящему времени описаны липосомные препараты самых разнообразных фармакологических средств, рентгенологических и сцинтиграфических трейсеров, токсинов, пептидов, белков и нуклеиновых кислот. Подавляющее большинство работ подобного рода проводили с противоопухолевыми препаратами (чаще всего, с антрациклиновыми) [8]. Наиболее часто в исследованиях по доставке лекарств использовали следующие пять типов липосом, отличающихся составом и действием in vivo: простые липосомы; стерически стабилизированные липосомы; направленные липосомы (иммунолипосомы); катионные липосомы; липосомы, чувствительные к физическим и химическим стимулам, таким как температура, свет и изменения значения $\mathrm{pH}$ [2, 10] (табл. 1).

Особую роль липосомы стали играть в связи с появлением нового поколения препаратов, получаемых методами биотехнологии и генной инженерии, таких как рекомбинантные белки, пептиды (биотехнологические ЛП), а также препараты на основе нуклеиновых кислот (генотерапевтические ЛП) в связи с чувствительностью указанных препаратов к химическому и ферментативному гидролизу [8, 39-41]. В случае генотерапии in vivo липосомные наноконтейнеры могут содержать плазмиду с последовательностью терапевтического гена, антисенс олигонуклеотиды или малые интерферирующие РНК [42-44]. Объем липосом позволяет включать в них гены различного размера [45]. Как и в случае с цитостатическими препаратами и парамагнитными контрастами, адресность доставки может быть достигнута с помощью векторных молекул, ковалентно пришитых к наружной поверхности липосом.

При использовании липосом в качестве ДНК-вакцин они удерживают антиген в своей капсуле и выполняют двойную функцию, выступая в качестве носителя антигена вакцины и иммуномодулятора $[46,47]$. В одной из работ в качестве ДНК-вакцины использовали последовательность S-антигена вируса гепатита B (pRc/CMV HBS), заключенного В катионные липосомы [47]. Мыши Balb/c были вакцинированы внутримышечно дважды на 0 и 21-й дни 10 мКг плазмидной ДНК на мышь. Уровни определяемых цитокинов в селезенке иммунизированных липосомным препаратом мышей после введения нативного HBsAg был в 4 раза выше уровня цитокинов у интактных мышей и животных, вакцинированных ДНК, что свидетельствует о возможности использования данной липосомной конструкции для вакцинации против гепатита В.

Для загрузки ДНК можно применять липосомы как с нейтрально заряженной наружной поверхностью, так и катионные или анионные липосомы. Преимуществом нейтральных липосом является то, что они гораздо дольше циркулируют в кровотоке, чем заряженные, обладают меньшей токсичностью и неспецифической сорбцией в органах и тканях. Однако их гораздо сложнее загрузить ДНК. При пассивной загрузке (т. е. при простом 
Таблица 1. Применение различных типов липосом для доставки лекарственных препаратов

\begin{tabular}{|c|c|c|c|c|c|}
\hline $\begin{array}{l}\text { Типы } \\
\text { липосом }\end{array}$ & Простые & $\begin{array}{l}\text { Стерически } \\
\text { стабилизированные }\end{array}$ & Иммунолипосомы & $\begin{array}{l}\text { Катионные } \\
\text { (lipoplexes) }\end{array}$ & $\begin{array}{l}\text { Термочувствительные } \\
\text { и фоточувствительные }\end{array}$ \\
\hline $\begin{array}{l}\text { Особенности } \\
\text { состава }\end{array}$ & $\begin{array}{l}\text { Фосфолипиды } \\
\text { (нейтральные } \\
\text { и/или отрицательно } \\
\text { заряженные) } \\
\text { и/или холестерин }\end{array}$ & $\begin{array}{l}\text { Фосфолипиды + } \\
\text { полиэтиленгли- } \\
\text { коль (ПЭГ) }\end{array}$ & $\begin{array}{l}\text { Модифицированные } \\
\text { ПЭГ-везикулы, } \\
\text { конъюгированные } \\
\text { с моноклональными } \\
\text { антителами или их } \\
\text { фрагментами, пептидами, } \\
\text { факторами роста, } \\
\text { гликопротеинами и др. }\end{array}$ & $\begin{array}{l}\text { Положительно } \\
\text { заряженные } \\
\text { липиды }\end{array}$ & $\begin{array}{l}\text { Фосфолипиды с температурой } \\
\text { фазового перехода, превышающей } \\
\text { температуру тела (термочувствитель- } \\
\text { ные). В состав везикул } \\
\text { фотоизомеризуемой липидной } \\
\text { молекулы входит 1,2-бис(4-(н-бутил) } \\
\text { фенилазо-4'-фенилбутироил)фосфа- } \\
\text { тидилхолин (Віs-Аzo РС) } \\
\text { в низких концентрациях. } \\
\text { Могут быть конъюгированы с ПЭГ } \\
\text { или с антителами (АТ) }\end{array}$ \\
\hline $\begin{array}{l}\text { Пути } \\
\text { введения }\end{array}$ & $\begin{array}{l}\text { Пероральный, } \\
\text { инъекционный, } \\
\text { ингаляционный, } \\
\text { наружный, } \\
\text { эндовитреальный }\end{array}$ & $\begin{array}{l}\text { Инъекционный, } \\
\text { пероральный }\end{array}$ & Инъекционный & $\begin{array}{l}\text { Инъекционный, } \\
\text { интраназальный }\end{array}$ & Инъекционный \\
\hline $\begin{array}{l}\text { Время } \\
\text { полувыведения }\end{array}$ & $\begin{array}{l}\text { От нескольких } \\
\text { минут до } 2-3 \text { ч }\end{array}$ & \multicolumn{2}{|c|}{ От 6-8 ч до нескольких суток } & $\begin{array}{l}\text { От нескольких } \\
\text { минут до 4-6 ч }\end{array}$ & Несколько суток \\
\hline $\begin{array}{l}\text { Основные } \\
\text { места } \\
\text { скопления }\end{array}$ & \multicolumn{2}{|c|}{ Печень, селезенка, легкие } & $\begin{array}{l}\text { Определяется } \\
\text { присоединенными } \\
\text { лигандами, печень, легкие }\end{array}$ & Печень, легкие & Опухолевые клетки \\
\hline $\begin{array}{l}\text { Механизм } \\
\text { действия }\end{array}$ & $\begin{array}{l}\text { Пассивное } \\
\text { нацеливание }\end{array}$ & $\begin{array}{l}\text { Пассивное } \\
\text { нацеливание }\end{array}$ & Направленный транспорт & $\begin{array}{l}\text { Пассивное } \\
\text { нацеливание }\end{array}$ & Направленный транспорт \\
\hline $\begin{array}{l}\text { Примеры } \\
\text { использования }\end{array}$ & $\begin{array}{l}\text { - в составе вакцин } \\
\text { против вирусных, } \\
\text { бактериальных } \\
\text { и паразитарных } \\
\text { инфекций [11]; } \\
\text { - доставка в } \\
\text { макрофаги имму- } \\
\text { номодуляторов, } \\
\text { цитотоксических и } \\
\text { противомикробных } \\
\text { соединений; } \\
\text { - лечение метаста- } \\
\text { зов после хирурги- } \\
\text { ческого удаления } \\
\text { первичных } \\
\text { опухолей [12, 13]; } \\
\text { - доставка лп } \\
\text { против внутрикле- } \\
\text { точных патогенных } \\
\text { микроорганизмов } \\
\text { [14], системной } \\
\text { грибковой } \\
\text { инфекции, Вич, } \\
\text { микобактериальной } \\
\text { инфекции [13]; } \\
\text { - диагностика в } \\
\text { качестве носителей } \\
\text { радиоизотопов } \\
\text { и контрастных } \\
\text { веществ для визуа- } \\
\text { лизации [12, 13]; } \\
\text { - носители } \\
\text { антигенов [12, 15] }\end{array}$ & $\begin{array}{l}\text { - накопление ЛП } \\
\text { в солидных } \\
\text { опухолях [16-18]; } \\
\text { - лечение } \\
\text { мелкоклеточного } \\
\text { рака легкого и } \\
\text { меланомы кожи } \\
\text { [19], лейкозов и } \\
\text { карциномы } \\
\text { легкого }[20,21]\end{array}$ & $\begin{array}{l}\text { - доставка лП в опухоль } \\
{[10,22-26] ;} \\
\text { - лечение хронического } \\
\text { В-лимфоцитарного } \\
\text { лейкоза и острого } \\
\text { Т-клеточного лейкоза [23], } \\
\text { различных лимфом [27]; } \\
\text { - терапия рака молочной } \\
\text { и щитовидной желез, } \\
\text { яичников, матки, легкого, } \\
\text { пищевода, желудка, } \\
\text { толстой и прямой кишки, } \\
\text { почки [23, 26, 28] }\end{array}$ & $\begin{array}{l}\text { - доставка } \\
\text { генетического } \\
\text { материала в } \\
\text { печень, } \\
\text { клеточная } \\
\text { терапия } \\
\text { эндотелиальных } \\
\text { опухолей } \\
\text { легких } \\
\text { [2, 29, 30]; } \\
\text { - антиангиогенная } \\
\text { терапия; } \\
\text { - лечение } \\
\text { опухолей шеи, } \\
\text { головы, } \\
\text { меланом [30] }\end{array}$ & - доставка ЛП в опухоль [2, 31] \\
\hline $\begin{array}{l}\text { Основные } \\
\text { преимущества }\end{array}$ & $\begin{array}{l}\text { Проникают в } \\
\text { относительно } \\
\text { малодоступные } \\
\text { очаги воспаления } \\
\text { (например, в мозг), } \\
\text { так как имеют } \\
\text { отрицательный } \\
\text { заряд [32, 33] }\end{array}$ & $\begin{array}{l}\text { Содержат ПЭГ, } \\
\text { препятствующий } \\
\text { опсонизации } \\
\text { липосом, } \\
\text { уменьшению их } \\
\text { распознавания } \\
\text { клетками ретику- } \\
\text { лоэндотелиальной } \\
\text { системы и } \\
\text { увеличению } \\
\text { времени } \\
\text { циркуляции } \\
\text { в кровотоке [34, 35] }\end{array}$ & $\begin{array}{l}\text { Антитела позволяют } \\
\text { модулировать } \\
\text { распределение липосом } \\
\text { в органах и тканях. } \\
\text { Оптимизация } \\
\text { терапевтических } \\
\text { свойств ЛС. Коррекция } \\
\text { действующей дозы }\end{array}$ & $\begin{array}{l}\text { В отличие от } \\
\text { отрицательно } \\
\text { заряженных или } \\
\text { нейтральных ли- } \\
\text { посом проникают } \\
\text { в сосуды } \\
\text { опухоли [36] }\end{array}$ & $\begin{array}{l}\text { Обладают большей } \\
\text { избирательностью действия } \\
\text { по сравнению со свободным } \\
\text { препаратом }[31,37,38]\end{array}$ \\
\hline
\end{tabular}


эмульгировании липидных компонентов в присутствии ДНК) в липосомы попадает лишь 10\% от общего количества ДНК, при использовании специальных приемов степень загрузки возможно увеличить до 40\% и выше, однако при использовании этих приемов, как правило, получаются липосомы крупного размера [45]. Высокая степень загрузки ДНК является основным преимуществом заряженных липосом. Недостатками катионных и анионных липосом является более высокая, чем у неполярных липосом, токсичность и неспецифическое проникновение в органы и ткани.

\section{Особенности контроля качества производства и готовых липосомных форм ЛП}

Основные этапы технологического процесса получения липосомных форм ЛП и контролируемые параметры следующие [48]:

1) получение липидной пленки и ее диспергирование/ деградация. Контролируемые параметры: количество остаточных органических растворителей в липидной пленке, процент включения активного вещества и размер липосом после диспергирования липидной пленки, стабильность, значение $\mathrm{pH}$;

2) получение липосом заданного размера, отделение невключенного активного вещества, стерилизация методом фильтрации. Контролируемые параметры: количество включенного активного вещества и размер липосом, концентрация липидных компонентов, стабильность, значение $\mathrm{pH}$;

3) лиосилизация. Контролируемые параметры: остаточная влажность, стабильность и процент включения ЛП в липосомы после регидратации лиофилизата.

Из перечисленных этапов технологического процесса можно заключить, что критические точки контроля качества липосомного препарата связаны с определением его значимых физико-химических свойств, поэтому при подаче досье для государственной регистрации липосомных форм ЛП необходимо изучить следующие общие параметры (рис. 1).
Одним из основных параметров, оказывающих влияние на ФК и ФД липосомных форм ЛП, является поведение активного вещества в физиологическом окружении, поэтому необходимо разработать надежные валидированные методы оценки высвобождения активного вещества in vitro для следующих целей:

- мониторинг имитации высвобождения действующего вещества из липосом в организме. При наличии оснований допустимо испытание на «вытекание» in vitro в релевантной среде при различных условиях (например, в диапазоне температур и значений $\mathrm{pH}$ );

- мониторинг стабильности при хранении для обеспечения постоянства серий;

- исследование стабильности и процесса приготовления в предполагаемых условиях применения.

В табл. 2 в качестве примера представлены основные показатели качества и параметры для паспортизации липосом [49, 50], используемых для доставки ДНК терапевтических генов.

Авторы полагают, что в зависимости от конкретной функции липосом (например, модификации распределения действующего вещества путем инкапсуляции в целях улучшения просиля безопасности) при разработке препарата следует также оценивать следующие дополнительные параметры:

- поддержание целостности липосомной готовой формы в плазме;

- характеристика процесса фазового перехода липидного бислоя (температура и энтальпия переходов);

- определение поверхностного заряда липосом;

- pH внутренней камеры липосом, наполняемых по градиенту $\mathrm{pH}$;

- если значимо, установление характеристик физического состояния активного вещества внутри липосомы (например, в случае доксорубицина - образование осадка);

- распределение активного вещества (например, на поверхности липосом, в бислое, внутренней среде и т. д.);

- в отношении конъюгированных (например, пегилированных) липосомных препаратов: качество и чистота пегилированного исходного материала, молекулярная

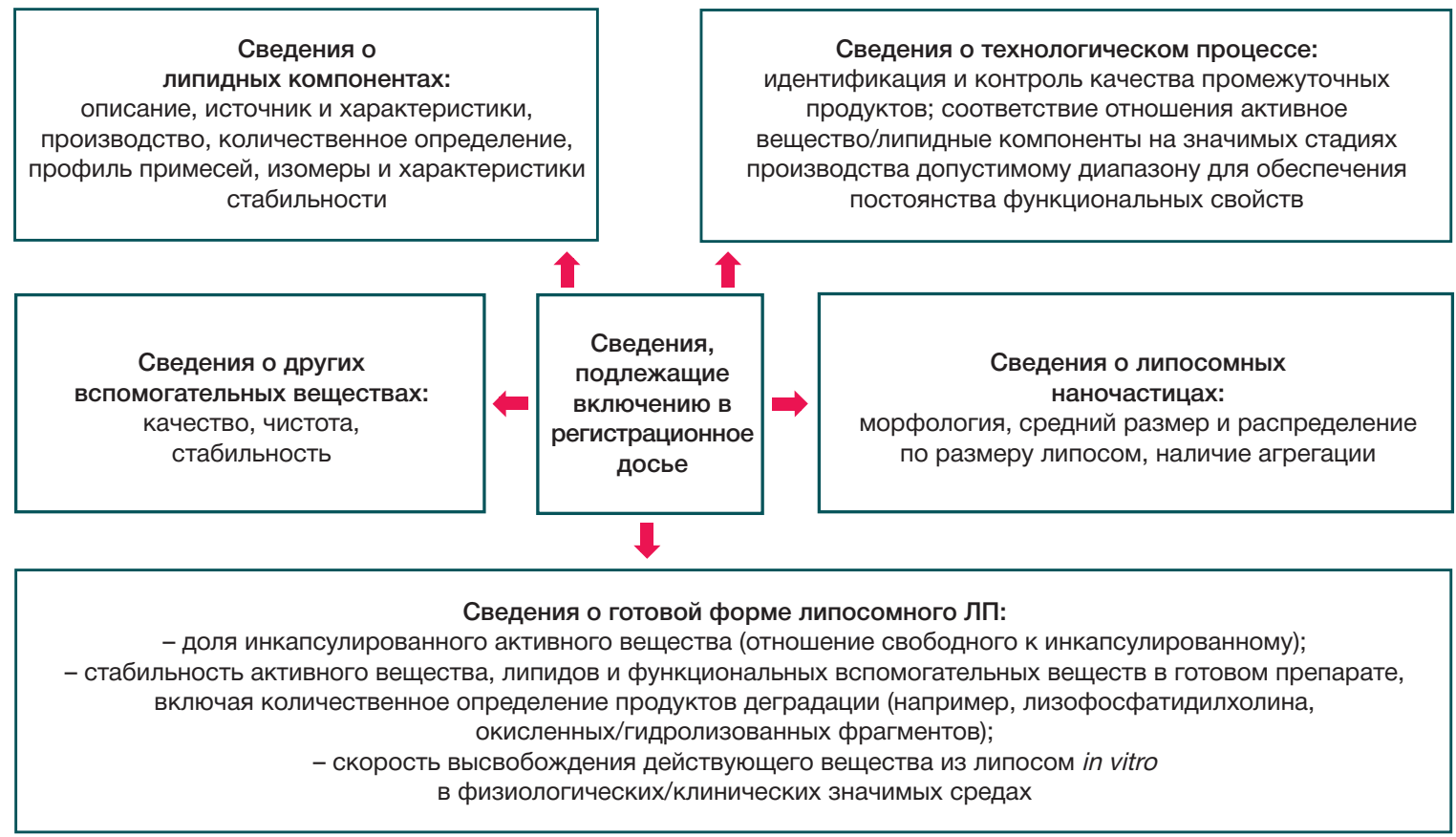

Рис. 1. Сведения о качественных характеристиках липосомных форм ЛП 
Таблица 2. Характеристики липосомных препаратов

\begin{tabular}{|c|c|c|}
\hline \multicolumn{2}{|r|}{ Параметры } & Аналитические/инструментальные методы \\
\hline \multicolumn{3}{|r|}{ Физические характеристики } \\
\hline 1 & Размер везикул и морфология поверхности & Электронная микроскопия \\
\hline 2 & $\begin{array}{l}\text { Распределение везикул по размерам } \\
\text { (субмикронный и микронный диапазоны) }\end{array}$ & Динамическое и лазерное светорассеяние, эксклюзионная хроматография (гель-фильтрация) \\
\hline 3 & Поверхностный заряд & Динамическое рассеяние света \\
\hline 4 & Поверхностный рН & рН-чувствительные пробы \\
\hline 5 & $\begin{array}{l}\text { Процент включения ДНК/процент } \\
\text { свободного препарата }\end{array}$ & $\begin{array}{l}\text { Метанол-хлороформная экстракция и центрифугирование на разделительных колонках, } \\
\text { ионообменная хроматография, спектрофотометрия, метод радиоактивных меток }\end{array}$ \\
\hline \multicolumn{3}{|r|}{ Химические характеристики } \\
\hline 1 & Концентрация фосфолипидов & Экстракция и центрифугирование на разделительных колонках \\
\hline 2 & Концентрация холестерина & Экстракция и центрифугирование на разделительных колонках \\
\hline 3 & Осмотичность & Осмометрия \\
\hline \multicolumn{3}{|r|}{ Биологические характеристики } \\
\hline 1 & Стерильность & Фармакопейный тест стерильности \\
\hline 2 & Пирогенность & ЛАЛ-тест (Limulus amebocyte lysate test) \\
\hline 3 & Токсичность & Мониторинг in vitro и in vivo, гистология \\
\hline
\end{tabular}

Таблица 3. Характеристики липосомных препаратов

\begin{tabular}{|c|c|c|}
\hline Страна & Документ & Некоторые аспекты \\
\hline \multirow{3}{*}{$\begin{array}{l}\text { Страны } \\
\text { Европейского } \\
\text { союза }\end{array}$} & $\begin{array}{l}\text { Reflection paper on the data requirements } \\
\text { for intravenous liposomal products developed } \\
\text { with reference to an innovator liposomal product/21 } \\
\text { February } 2013 \text { EMA/CHMP/806058/2009/Rev. 02, } \\
\text { Committee for Human Medicinal Products (CHMP) }\end{array}$ & $\begin{array}{l}\text { Особенности контроля качества: } \\
\text { - состав и подлинность компонентов (липидные компоненты } \\
\text { и вспомогательные вещества); } \\
\text { - соотношение активное вещество/липиды; } \\
\text { - морфология липосом, средний размер и распределение } \\
\text { по размерам, агрегация; } \\
\text { - фракция инкапсулированного активного вещества } \\
\text { (количество свободного/включенного); } \\
\text { - стабильность активного вещества, липидов, } \\
\text { вспомогательных веществ, критических продуктов разложения; } \\
\text { - іn vitro скорость высвобождения вещества препарата } \\
\text { из липосом в физиологически/клинически значимых средах; } \\
\text { - стабильность; } \\
\text { - восстановление; } \\
\text { - поддержание целостности липосомной рецептуры в плазме }\end{array}$ \\
\hline & $\begin{array}{l}\text { Recommendations. Commission recommendation } \\
\text { of } 18 \text { October } 2011 \text { on the definition of nanomaterial } \\
\text { (Text with EEA relevance) }(2011 / 696 / E U)\end{array}$ & Определение наноматериалов \\
\hline & $\begin{array}{l}\text { Reflection paper on surface coatings: general } \\
\text { issues for consideration regarding parenteral } \\
\text { administration of coated nanomedicine } \\
\text { products/22 May } 2013 \text {, EMA } / 325027 / 2013 \text {, } \\
\text { Committee for Medicinal Products } \\
\text { for Human Use (CHMP) }\end{array}$ & $\begin{array}{l}\text { Приведены основные критические показатели качества, } \\
\text { а также требования к клиническим и доклиническим } \\
\text { исследованиям. Особое внимание уделяется следующим аспектам: } \\
\text { - наличие покрытия может повлиять на критические свойства } \\
\text { нанопрепаратов с точки зрения безопасности и эффективности. } \\
\text { Физико-химическая природа покрытия, равномерность покрытия } \\
\text { поверхности и его стабильность (как с точки зрения прикрепления, } \\
\text { так и с точки зрения деградации) будут определять ФК } \\
\text { и биораспределение продукта; } \\
\text { - в некоторых случаях материал покрытия может вызвать } \\
\text { новые биологические реакции, не наблюдаемые ни для } \\
\text { материала покрытия, ни для активного вещества по отдельности }\end{array}$ \\
\hline \multirow[t]{2}{*}{ США } & $\begin{array}{l}\text { Guidance for Industry. Liposome Drug Products Chemistry, } \\
\text { Manufacturing, and Controls; Human Pharmacokinetics and } \\
\text { Bioavailability; and Labeling Documentation. } \\
\text { - U.S. Department of Health and Human Services Food } \\
\text { and Drug Administration Center for Drug Evaluation } \\
\text { and Research, } 2002\end{array}$ & $\begin{array}{l}\text { Краткое описание липосом, критические этапы их производства } \\
\text { и контроля качества, приведены рекомендации по проведению } \\
\text { исследований по ФК и биодоступности липосомных ЛП } \\
\text { и требования к маркировке. Руководство содержит общие } \\
\text { принципы и рекомендации для регистрации препаратов } \\
\text { данного класса }\end{array}$ \\
\hline & $\begin{array}{l}\text { USP } 41-N F 36<1>\text { Injections and implanted } \\
\text { drug products (parenterals)-product quality tests }\end{array}$ & $\begin{array}{l}\text { Содержит определение липосом и липосомного лП, } \\
\text { указывается, что при контроле качества для липосом } \\
\text { требуются как общие испытания, так и специальные тесты }\end{array}$ \\
\hline Китай & $\begin{array}{l}\text { Pharmacopoeia of the Peoples Republic of China. } \\
\text { Beijing: People's Medical Publishing Hous. } \\
\text { 2010; (2). p. A244-245 }\end{array}$ & $\begin{array}{l}\text { Приведены определения различных наночастиц, требования, } \\
\text { критерии и методики контроля качества нанопрепаратов. } \\
\text { Указаны показатели, которые следует контролировать при } \\
\text { производстве и хранении продуктов (например, остаточные } \\
\text { количества органических растворителей, форма, размер частиц } \\
\text { и их распределение, скорость инкапсулирования и количество } \\
\text { лекарственных средств в липосомах, степень окисления } \\
\text { липосом и др.) }\end{array}$ \\
\hline
\end{tabular}


масса конъюгированного липида и распределение по размеру (дисперсность), расположение ПЭГ на поверхности, стабильность конъюгата.

Необходимо определить перечень испытаний, которым планируется подвергать каждую серию липосомного препарата рутинно. Данный перечень должен основываться на параметрах, использованных для характеристики препарата в соответствии с вышеописанными требованиями.

\section{Нормативно-правовое регулирование липосомных препаратов в мире}

Примеры требований мировых регуляторных органов к производству, контролю качества, проведению доклинических и клинических исследований липосомных форм ЛП приведены в документах, представленных в табл. 3.

\section{ВЫВОДЫ}

Липосомные системы доставки позволяют разработчику изменять и контролировать параметры всасывания и высвобождения действующего вещества. Лекарственные формы на основе липосом, как правило, отличаются меньшей токсичностью, возможностью адресной доставки лекарственного средства и меньшим риском развития нежелательных реакций. Использование инновационных препаратов, содержащих липосомы, конъюгированные с антителами, позволяет максимально точно определить локус высвобождения активного компонента. Однако увеличение сложности структуры препарата неизбежно приводит к увеличению числа критических точек производства, а также к расширению списка параметров, подлежащих контролю, которые являются показателями качества. Наряду с использованием классических методов контроля качества, оценивают также физико-химические свойства липосомной фракции: форму, размер и заряд частиц; эффективность конъюгации маркеров; равномерность распределения действующего вещества. Ключевые методы оценки параметров липосом основаны на оптических эффектах: динамическое и лазерное светорассеяние, электронная микроскопия.

\section{Литература}

1. Краснопольский Ю. М., Степанов А. Е., Швец В. И. Технологические аспекты получения липосомальных препаратов в условиях GMP. Биофарм журнал. 2009; (3): 18-29.

2. Барышников А. Ю. Наноструктурированные липосомальные системы как средство доставки противоопухолевых препаратов. Вестник РАМН. 2012; (3): 23-31.

3. Hobbs SK, Monsky WL, Yuan F et al. Regulation of transport pathways in tumor vessels: role of tumor type and microenvironment. Proc Natl Acad Sci USA. 1998; (95): 4607-12.

4. Швец В. И., Каплун А. П., Краснопольский Ю. М., Степанов А. Е., Чехонин В. П. От липосом семидесятых к нанобиотехнологии XXI века. Российские нанотехнологии. 2008; 3 (11-12): 6-20.

5. Love WG, Amos N, Kellaway IW, Williams BD. Specific accumulation of cholesterol-rich liposomes in the inflammatory tissue of rats with adjuvant arthritis. Ann Rheum Dis. 1990; 49 (8): 611-14.

6. Чехонин В. П., Баклаушев В. П., Юсубалиева Г. М. Моделирование и иммуногистохимический анализ глиомы С6 in vivo. Клеточные технологии в биологии и медицине. 2007; (2): 65-73.

7. Чехонин В. П., Жирков Ю. А., Гурина О. И. ПЭГилированные иммуннолипосомы, специфичные к астроцитам. Доклады Академии наук. 2003; 391 (6): 1-7.

8. Чехонин В. П., Гурина О. И., Дмитриева Т. В. Моноклональные антитела к нейроспецифическим белкам. М.: Медицина, 2007; 344 c.

9. Errede M, Benagiano V, Girolamo F et al. Differential expression of connexin43 in foetal, adult and tumour-associated human brain endothelial cells. Histochem J. 2002; (34): 265-71.

10. Immordino ML, Dosio F, Cattel L. Stealth liposomes: review of the basic science, rationale and clinical applications, existing and potential. Int J Nanomedicine. 2006; 1 (3): 297-315.

11. Felnerova D, Viret J-F, Gluck R, Moser C. Liposomes and virosomes as delivery systems for antigens, nucleic acids and drugs. Curr Opin Biotechnol. 2004; (15): 518-29.

12. Barenholz Y. Liposome application: problems and prospects. Curr Opin Colloid Interface Sci. 2001; (6): 66-77.

13. Vasir JK, Reddy MK, Labhasetwar VD. Nanosystems in drug targeting: opportunities and challenges. Curr Nanoscience. 2005; $1(1): 47-64$.

14. Basu MK. Liposomal delivery of antileishmanial agents. J Applied Research. 2005; 5 (1): 221-36.
15. Zurbriggen $\mathrm{R}$, Amacker $\mathrm{M}$, Krammer AR. Immunopotentiating reconstituted influenza virosomes. In: G. Gregoriadis, editor. Liposome technology. 3rd edn. Vol. I. Liposome preparation and related techniques. New York: Informa Healthcare USA, 2007; 85-96.

16. Fang J, Sawa T, Maeda H. Factors and mechanism of «epr» effect and the enhanced antitumor effects of macromolecular drugs including smancs. Adv Exp Med Biol. 2003; (519): 29-49.

17. Greish K, Fang J, Inutsuka T et al. Macromolecular therapeutics: advantages and prospects with special emphasis on solid tumour targeting. Clin Pharmacokinet. 2003; (42): 1089-105.

18. Maeda $\mathrm{H}$. The enhanced permeability and retention (epr) effect in tumor vasculature: the key role of tumor-selective macromolecular drug targeting. Adv Enzyme Regul. 2001; (41): 189-207.

19. Haley B, Frenkel E. Nanoparticles for drug delivery in cancer treatment. Urologic Oncology: Seminars and Original Investigations. 2008; (26): 57-64.

20. Ланцова А. В. Создание и биотерапевтическое изучение липосомальных лекарственных форм противоопухолевых препаратов производных нитрозомочевины [диссертация]. М., 2006; 173 C.

21. Ланцова А. В., Оборотова Н. А. Перетолчина Н. М. Сравнительное изучение противоопухолевой активности липосомальных лекарственных форм препаратов производных нитрозоалкилмочевины. Сибирский онкологический журнал. 2005; 2 (14): 25-9.

22. Allen TM. Ligand-targeted therapeutics in anticancer therapy. Nat Rev Cancer. 2002; 2 (10): 750-63.

23. Толчева Е. В. Создание конструкции иммунолипосомы и изучение иммунолипосомальной формы противоопухолевого препарата доксорубицин [диссертация]. М., 2007; 109 с.

24. Соколова Д. В., Тазина Е. В., Кортава М. А. Анти-CD40 и анти-HLA-DR иммунолипосомальные формы доксорубицина: технология получения и антигенспецифичность in vivo. Российский биотерапевтический журнал. 2010; 9 (2): 90.

25. Соколова Д. В., Тазина Е. В., Кортава М. А. и др. Анти-MUC1 иммунолипосомальная форма доксорубицина: технология получения и антигенспецифичность in vitro. Российский биотерапевтический журнал. 2010; 9 (3): 21.

26. Хугаева О. В., Кортава М. А., Соколова Д. В. и др. Получение липосомального митоксантрона. Материалы IX Всеросс. науч.-практ. конф. “Отечественные противоопухолевые 
препараты». Российский биотерапевтический журнал. 2010; 9 (2): 91.

27. Насонов Е. Л. Перспективы применения ритуксимаба при аутоиммунных заболеваниях человека. Российский медицинский журнал. 2007; 15 (26): 1-6.

28. Соколова Д. В. Иммунолипосомальные конструкции доксорубицина и модели для их доклинического исследования [диссертация]. М., 2011; 122 с.

29. Kawakami S, Fumoto S, Nishikawa M et al. In vivo gene delivery to the liver using novel galactosylated cationic liposomes. Pharmaceuttic Research. 2000; 17 (3): 306-13.

30. Dass CR, Choong PFM. Targeting of small molecule anticancer drugs to the tumor and its vasculature using cationic liposomes: lessons from gene therapy. Cancer Cell Int. 2006; 6 (17): 1-9.

31. Ponce AM, Wright A, Dewhirst MW, Needham D. Targeted bioavailability of drugs by triggered release from liposomes. Future Lipidol. 2006; 1 (1): 25-34.

32. Jain S, Mishra V, Singh P et al. RGD-anchored magnetic liposomes for monocytes/neutrophils-mediated brain targeting. Int J Pharm. 2003; 261 (1-2): 43-55.

33. Qin J, Chen D, Hu H et al. Surface modification of RGD-liposomes for selective drug delivery to monocytes/Neutrophils in brain. Chem Pharm Bull. 2007; 55 (8): 1192-7.

34. Campbell RB, Fukumura D, Brown EB et al. Cationic charge determines the distribution of liposomes between the vascular and extravascular compartments of tumors. Cancer Res. 2002; (62): 6831-6.

35. Ambegia $E$, Ansell $S$, Cullis $P$ et al. Stabilized plasmid-lipid particles containing PEG-diacylglycerols exhibit extended circulation lifetimes and tumor selective gene expression. Biochim Biophys Acta. 2005; 1669 (2): 155-63.

36. Dass CR. Improving anti-angiogenic therapy via selective delivery of cationic liposomes to tumor vasculature. Int J Pharm. 2003; 267 (1-2): 1-12.

37. Тазина Е. В., Мещерикова В. В., Игнатьева Е. В. и др Биосармацевтические исследования термочувствительной липосомальной лекарственной формы доксорубицина Российский биотерапевтический журнал. 2009; 1 (8): 40-7.

\section{References}

1. Krasnopolsky YuM, Stepanov AE, Shvets VI. Technological aspects of production of liposomal preparations under GMP conditions. Biofarm J. 2009; 3: 18-29.

2. Baryshnikov AYu. Nanostructured liposomal systems as a means of delivery of anticancer drugs. Vestnik RAMS. 2012; 3: 23-31.

3. Hobbs SK, Monsky WL, Yuan F. et al. Regulation of transport pathways in tumor vessels: role of tumor type and microenvironment. Proc Natl Acad Sci USA. 1998; 95: 4607-4612.

4. Shvets IV, Kaplun AP, Krasnopolsky YuM. et al. From liposome seventies to nanobiotechnology XXI century. Ross nanotechnologies. 2008; 3 (11-12): 6-20.

5. Love WG, Amos N, Kellaway IW, Williams BD. Specific accumulation of cholesterol-rich liposomes in the inflammatory tissue of rats with adjuvant arthritis. Ann Rheum Dis. 1990; 49 (8): 611-614.

6. Chekhonin VP, Baklaushev VP, Yusubalieva GM. et al. Modeling and immunohistochemical analysis of glioma C6. Cell technol in biol and med. 2007: 2: 65-73.

7. Chekhonin VP, Zhirkov YuA, Gurina Ol. et al. The Pegylated immunoliposome specific to astrocytes. Dokl. RAN. 2003; 391 (6): $1-7$.

8. Chekhonin VP, Gurina OI, Dmitrieva TB. Monoclonal antibodies to neurospecific proteins. M.: Medicine, 2007; 344.

9. Errede M, Benagiano V, Girolamo F et al. Differential expression of connexin43 in foetal, adult and tumour-associated human brain endothelial cells. Histochem J. 2002; 34: 265-271.

10. Immordino ML, Dosio F, Cattel L. Stealth liposomes: review of the basic science, rationale and clinical applications, existing and potential. Int J Nanomedicine. 2006; 1 (3): 297-315.

11. Felnerova D, Viret J-F, Gluck R, Moser C. Liposomes and
38. Huang Z, Szoka FC. Bioresponsive liposomes and their use for macromolecular delivery. In: G. Gregoriadis, editor. Liposome technology. 3rd edn. Vol. I. Liposome preparation and related techniques. New York: Informa Healthcare USA, 2007; p. 165-96.

39. Березов Т. Т., Яглова Н. В., Дмитриева Т. Б. и др. Направленный транспорт лекарственных средств с помощью липосом. Вестник РАМН. 2004; 5: 42-7.

40. Wu D, Pardridge WM. Neuroprotection with noninvasive neurotrophin delivery to the brain. Proc Natl Acad Sci USA. 1999; (96): 254-9.

41. Shi N, Pardridge WM. Noninvasive gene targeting to the brain. Proc Natl Acad Sci USA. 2000; 97 (13): 7567-72.

42. Pal A, Ahmad A, Khan S et al. Systemic delivery of RafsiRNA using cationic liposomes silences Raf in xenograft model of human prostate cancer. Int J Oncol. 2005; 26 (4): 1087-91.

43. Omidi Y, Barar J, Akhtar S. Toxicogenomics of cationic lipidbased vectors for gene therapy: impact of microarray. Curr Drug Del. 2005; 2 (4): 429-41.

44. Oliveira S, Storm G, Schiffelers. Targeted delivery of siRNA. J Biomed Biotechnol. 2006; (2006): 1-7.

45. Miyazaki M, Obata $\mathrm{Y}$, Abe $\mathrm{K}$ et al. Gene transfer using nonviral delivery systems. Perit Dial Int. 2006; (26): 633-40.

46. Aguilar JC. Vaccine adjuvants revisited. Vaccine. 2007; (25): 3752-62.

47. Perrie Y, Frederik PM, Gregoriadis G. Liposome-mediated DNA vaccination: the effect of vesicle composition. Vaccine. 2001; (19): 3301-10.

48. Фармацевтическая разработка: концепция и практические рекомендации. В книге: Быковский С. Н., Василенко И. А., Демина Н. Б., Шохин И. Е., Новожилов О. В., Мешковский А. П., Спицкий О. Р., редакторы. Научно-практическое руководство для фармацевтической отрасли. М.: Перо, 2015; 472 с.

49. Lu D, Hickey AJ. Liposomal dry powders as aerosols for pulmonary delivery of proteins. AAPS Pharm Sci Tech. 2005; 6 (4): 641-8.

50. De Lima MCP, Simoes $S$, Pires $P$ et al. Cationic lipid-DNA complexes in gene delivery: from biophysics to biological applications. Adv Drug Del Rev. 2001; (47): 277-94.

virosomes as delivery systems for antigens, nucleic acids and drugs. Curr Opin Biotechnol. 2004; 15: 518-529.

12. Barenholz Y. Liposome application: problems and prospects. Curr Opin Colloid Interface Sci. 2001; 6: 66-77.

13. Vasir JK, Reddy MK, Labhasetwar VD. Nanosystems in drug targeting: opportunities and challenges. Curr Nanoscience. 2005; 1 (1): 47-64.

14. Basu MK. Liposomal delivery of antileishmanial agents. J Applied Research. 2005; 5 (1): 221-236.

15. Zurbriggen R, Amacker M, Krammer AR. Immunopotentiating reconstituted influenza virosomes. In: G. Gregoriadis eds. Liposome technology. 3rd edn. Vol. I. Liposome preparation and related techniques. New York: Informa Healthcare USA, 2007; 85-96.

16. Fang J, Sawa T, Maeda H. Factors and mechanism of «epr» effect and the enhanced antitumor effects of macromolecular drugs including smancs. Adv Exp Med Biol. 2003; 519: 29-49.

17. Greish K, Fang J, Inutsuka T. et al. Macromolecular therapeutics: advantages and prospects with special emphasis on solid tumour targeting. Clin Pharmacokinet. 2003; 42: 1089-1105.

18. Maeda $\mathrm{H}$. The enhanced permeability and retention (epr) effect in tumor vasculature: the key role of tumor-selective macromolecular drug targeting. Adv Enzyme Regul. 2001; 41: 189-207.

19. Haley B, Frenkel E. Nanoparticles for drug delivery in cancer treatment. Urologic Oncology: Seminars and Original Investigations. 2008; 26: 57-64.

20. Lantsova AV. Creation and biopharmaceutical study of liposomal dosage forms of anticancer drugs derived from nitrosourea. Abstract dis kand farm. sciences. Moscow, 2006; 173.

21. Lantsova AV, Oborotova NA, Peretolchina NM et al. Comparative 
study of the antitumor activity of the liposomal dosage forms of drugs, derivatives of nitrozomocevina. Sibirs oncologist J. 2005; 2 (14): 25-29.

22. Allen TM. Ligand-targeted therapeutics in anticancer therapy. Nat Rev Cancer. 2002; 2 (10): 750-763.

23. Tolcheva EV. Design of immunoliposomes and study of immunoliposomal form of anticancer drug doxorubicin. Abstract dis kand Biol sciences. M., 2007; 109 p.

24. Sokolova DV, Tazina EV, Kortava MA. et al. Anti-CD40 and antiHLA-DR immunoliposomal form doxorubicin: technology of production and antigen specificity in vivo. Ross biotherapeutic $\mathrm{J}$. 2010; 9 (2): 90.

25. Sokolova DV, Tazina EV, Kortava MA et al. Anti-MUC1 immunoliposomal form of doxorubicin: technology of production and antigen specificity in vitro. Ross biotherapeutic J. 2010; 9 (3): 21.

26. Khugaeva OV, Kortava MA, Sokolova DV et al. Receiving liposomal mitoxantrone/materials of the IX all-Russian. scientific.prakt. Conf. "Domestic anticancer drugs". Ross biotherapeutic J. 2010; 9 (2): 91.

27. Nasonov EL. Prospects of rituximab use in autoimmune diseases of a person. Rus Med J. 2007; 15 (26): 1-6.

28. Sokolova DV. Immunoliposomal constructions of doxorubicin and models for their preclinical study. Abstract dis kand Biol sciences. M., 2011; 122.

29. Kawakami S, Fumoto S, Nishikawa M et al. In vivo gene delivery to the liver using novel galactosylated cationic liposomes. Pharmaceuttic Research. 2000; 17 (3): 306-313.

30. Dass CR, Choong PFM. Targeting of small molecule anticancer drugs to the tumor and its vasculature using cationic liposomes: lessons from gene therapy. Cancer Cell Int. 2006; 6 (17): 1-9.

31. Ponce AM, Wright A, Dewhirst MW, Needham D. Targeted bioavailability of drugs by triggered release from liposomes. Future Lipidol. 2006; 1 (1): 25-34.

32. Jain S, Mishra V, Singh $P$ et al. RGD-anchored magnetic liposomes for monocytes/neutrophils-mediated brain targeting. Int J Pharm. 2003; 261 (1-2): 43-55.

33. Qin J, Chen D, Hu H et al. Surface modification of RGD-liposomes for selective drug delivery to monocytes/Neutrophils in brain. Chem Pharm Bull. 2007; 55 (8): 1192-1197.

34. Campbell RB, Fukumura D, Brown EB et al. Cationic charge determines the distribution of liposomes between the vascular and extravascular compartments of tumors. Cancer Res. 2002; 62: 6831-6836.

35. Ambegia E, Ansell S, Cullis $P$ et al. Stabilized plasmid-lipid particles containing PEG-diacylglycerols exhibit extended circulation lifetimes and tumor selective gene expression. Biochim Biophys Acta. 2005; 1669 (2): 155-163.

36. Dass $\mathrm{CR}$. Improving anti-angiogenic therapy via selective delivery of cationic liposomes to tumor vasculature. Int J Pharm. 2003; 267 (1-2): 1-12.

37. Tazina EV, Mescheryakova W, Ignatieva EV et al. Biopharmaceutical studies of temperature-sensitive liposomal formulations of doxorubicin. Ross biotherapeutic J. 2009; 1 (8): 40-47.

38. Huang Z, Szoka FC. Bioresponsive liposomes and their use for macromolecular delivery. In: G. Gregoriadis eds. Liposome technology. 3rd edn. Vol. I. Liposome preparation and related techniques. New York: Informa Healthcare USA, 2007; 165-196.

39. Chekhonin VP, Zhirkov YuA, Aglow NV et al. Directed transport of drugs using liposomes. Vestn RAMS. 2004; 5: 42-47.

40. Wu D, Pardridge WM. Neuroprotection with noninvasive neurotrophin delivery to the brain. Proc Natl Acad Sci USA. 1999; 96: 254-259.

41. Shi N, Pardridge WM. Noninvasive gene targeting to the brain. Proc Natl Acad Sci USA. 2000; 97 (13): 7567-7572.

42. Pal A, Ahmad A, Khan $S$ et al. Systemic delivery of RafsiRNA using cationic liposomes silences Raf in xenograft model of human prostate cancer. Int J Oncol. 2005; 26 (4): 1087-1091.

43. Omidi $Y$, Barar J, Akhtar S. Toxicogenomics of cationic lipidbased vectors for gene therapy: impact of microarray. Curr Drug Del. 2005; 2 (4): 429-441.

44. Oliveira S, Storm G, Schiffelers. Targeted delivery of siRNA. J Biomed Biotechnol. 2006; 2006: 1-7.

45. Miyazaki M, Obata $\mathrm{Y}$, Abe $\mathrm{K}$ et al. Gene transfer using nonviral delivery systems. Perit Dial Int. 2006; 26: 633-640.

46. Aguilar JC. Vaccine adjuvants revisited. Vaccine. 2007; 25: 37523762.

47. Perrie Y, Frederik PM, Gregoriadis G. Liposome-mediated DNA vaccination: the effect of vesicle composition. Vaccine. 2001; 19: 3301-3310.

48. Pharmaceutical development: concept and practical recommendations. Scientific-practical guide for the pharmaceutical industry / ed. by Bykov SN, Vasilenko IA, Demina NB, Shokhin IE, Novojilov OV, Meshkovsky AP, Spitskov ORM. Pero, 2015; 472 p.

49. Lu D, Hickey AJ. Liposomal dry powders as aerosols for pulmonary delivery of proteins. AAPS Pharm Sci Tech. 2005; 6 (4): 641-648.

50. De Lima MCP, Simoes S, Pires $P$ et al. Cationic lipid-DNA complexes in gene delivery: from biophysics to biological applications. Adv Drug Del Rev. 2001; 47: 277-294. 